\title{
Utility of modified Laboratory Risk Indicator for Necrotizing Fasciitis (MLRINEC) score in distinguishing necrotizing from non- necrotizing soft tissue infections
}

\author{
Po-Han Wu' ${ }^{1}$ Kai-Hsiang Wu' ${ }^{1}$, Cheng-Ting Hsiao ${ }^{1,2}$, Shu-Ruei Wu ${ }^{3}$ and Chia-Peng Chang ${ }^{1 *}$
}

\begin{abstract}
Background: We conducted this study to promote a modified Laboratory Risk Indicator for Necrotizing Fasciitis (MLRINEC) score and evaluate the utility in distinguishing necrotizing fasciitis (NF) from other soft-tissue infections.

Method: A retrospective cohort study of hospitalized patients with NF diagnosed by surgical finding was conducted in two tertiary hospital in southern Taiwan between January 2015 and January 2020. Another group was matched by controls with non-necrotizing soft tissue infections based on time, demographics, and immune status. Data such as infectious location, comorbidities, and laboratory findings were recorded and compared. Logistics regression were used to determine the association with NF after adjustment for confounders and MLRINEC score was developed by then. Receiver operating curve (ROC) and the area under the curve (AUC) were used to evaluate its discriminating ability.

Result: A total of 303 patients were included; 101 in NF group and 202 in non-NF group. We added serum lactate and comorbid liver disease to the original LRINEC score and re-defined the cut-off values for 3 variables to develop the MLRINEC score. The cut-off value for MLRINEC score was 12 points with corresponding sensitivity of $91.8 \%$ and a specificity of $88.4 \%$, and the area under ROC (AUC) was $0.893(95 \% \mathrm{Cl}, 0.723$ to $0.948 ; p<0.01$ ).

Conclusion: MLRINEC score shows a high sensitivity and specificity in distinguishing NF from non-necrotizing softtissue infections. Patients with a MLRINEC score > 12 points should be highly suspected of presence of necrotizing fasciitis.
\end{abstract}

Keywords: Necrotizing fasciitis, Modified LRINEC, Predictor

\section{Introduction}

Necrotizing fasciitis (NF) is a severe, rapidly progressive disease that is characterized by the infection of subcutaneous tissue and fascia, resulting in extensive fascial necrosis [1]. The gold standard management for NF is rapid debridement and broad-spectrum antibiotics [2].

\footnotetext{
* Correspondence: giovanni850730@gmail.com

'Department of Emergency Medicine, Chang Gung Memorial Hospital, No.6, Sec. W., Jiapu Rd., Puzi City, Chiayi County 613, Taiwan (R.O.C.)

Full list of author information is available at the end of the article
}

Even under rapid and timely management, the risk of mortality and morbidity, such as amputation and multiorgan dysfunction, remains high [3-5]. Early recognition of patients at risk of NF is an essential point to improve outcomes [6]. However, distinguishing necrotizing softtissue infections from non-necrotizing soft-tissue infections in their early course is difficult. Biochemistry laboratory markers, ultrasonography, and magnetic resonance imaging were used in early differential diagnosis $[7,8]$. Wong et al. developed the Laboratory Risk

(c) The Author(s). 2021, corrected publication 2022 . Open Access This article is licensed under a Creative Commons Attribution 4.0 International License, which permits use, sharing, adaptation, distribution and reproduction in any medium or format, as long as you give appropriate credit to the original author(s) and the source, provide a link to the Creative Commons licence, and indicate if changes were made. The images or other third party material in this article are included in the article's Creative Commons licence, unless indicated otherwise in a credit line to the material. If material is not included in the article's Creative Commons licence and your intended use is not permitted by statutory regulation or exceeds the permitted use, you will need to obtain permission directly from the copyright holder. To view a copy of this licence, visit http://creativecommons.org/licenses/by/4.0/ The Creative Commons Public Domain Dedication waiver (http://creativecommons.org/publicdomain/zero/1.0/) applies to the data made available in this article, unless otherwise stated in a credit line to the data. 
Indicator for Necrotizing Fasciitis (LRINEC) score [9], which demonstrated high sensitivity in discriminating NF from other soft-tissue infections. However, recent studies on the LRINEC may have reported overpraised results. In different settings, the sensitivity of the LRIN EC was $43.2-80.0 \%$ for a score of $\geq 6$ and $28.6-68.4 \%$ for a score of $\geq 8$ [10-12]. Furthermore, some studies have shown the LRINEC to be non-relevant [11, 13]. In this study, we modified the original LRINEC score based on the data on matched cases and controls to develop a new score, the modified LRINEC (MLRINEC) score, and this study was conducted to present the novel score and evaluate its discrimination ability.

\section{Material and methods}

\section{Patient selection}

Under the approval of institutional review board, a retrospective cohort study was conducted. The medical records of patients who met the inclusion criteria of surgically proven NF and who received management between January 2015 and January 2020 in two tertiary hospitals were reviewed. Selected comorbidities and initial laboratory values were extracted through medical chart review. In total, 101 patients with NF were identified and assigned to the case group. At the selected time window, control patients were randomly selected from 841 patients with an admission diagnosis of nonnecrotizing soft-tissue infections, which was identified according to the International Classification of Diseases, Ninth Revision, Clinical Modification (ICD-9-CM) codes 528.3 (cellulitis and abscess of oral soft tissues), 681.00681.9 (cellulitis and abscess of the finger and toe), and 682.0-682.9 (other cellulitis and abscess). NF cases were matched to the control patients in a ratio of 1:2 using the propensity score based on the following variables: age, sex, initial vital signs, admission time, and immune status (immunocompromised or not). The $\mathrm{R}$ software was used to perform the matching process using the "MatchIt" package, with a caliper value of 0.25 standard deviation of the logit of a propensity score. Later, 202 control patients were included in the control group.

\section{Data collection and measurement}

Age, sex, vital signs in the emergency department (ED), admission date, the presence of comorbidities (i.e., cerebrovascular disease, heart disease, pulmonary disease, liver disease, kidney disease, peripheral vascular disease, malignancy, and diabetes), serum lactate, and LRINEC score, including $\mathrm{C}$-reactive protein, total white blood cell count, hemoglobin level, blood glucose, sodium concentration, and serum creatinine, were analyzed. After data collection was completed, random chart reviews were performed to ensure accuracy. All blood samples were collected upon arrival to the ED.

\section{Statistical analysis and MLRINEC score}

All data were analyzed using the statistical package for the social sciences software, version 20.0 (IBM Corp., Armonk, NY, USA). Continuous variables were analyzed using the $t$ test, and categorical variables were analyzed using the chi-square test, except for cases where $20 \%$ of the cells had expected counts of less than 5 , in which case, Fisher's exact test was used. The receiver operating characteristic (ROC) curve to determine the optimal cut-off value for each variable was plotted, corresponding to the maximized Youden index. Area under the ROC curve (AUC) analysis was used to evaluate the discrimination ability of the MLRINEC score.

Logistic regression analysis was performed to determine the independent effects of each variable on the development of NF using the entry method after adjusting for age, sex, and initial vital signs. To establish the score system, odds ratio for independent variables was rounded up and the total score for each patient was calculated by summing up the scores (Table 2). Then, the ROC curve and AUC were used to indicate the discrimination ability of the MLRINEC score, and the optimal cutoff value and corresponding sensitivity and specificity were determined. $P$ values of less than 0.05 were considered to be statistically significant.

\section{Results}

In this study, 101 patients with NF were enrolled, and 202 patients with non-necrotizing soft-tissue infections were matched and included in the control group. Using the propensity score matching method, the patients in the NF and non-NF groups exhibited almost the same basic characteristics. The patients in the NF group had a higher incidence of liver and kidney diseases than those in the non-NF group (34.7\% vs $14.9 \%$ for liver disease, $P$ $<0.01$ and $38.6 \%$ vs $12.4 \%$ for kidney disease, $P<0.01$ ). Elevated lactate levels were independently associated with the mortality rate in critically ill patients [14]. Even intermediate levels of initial serum lactate were an indicator of mortality, organ dysfunction, and shock in patients with severe sepsis in the ED [15]. In hospitalized patients, increased lactate levels indicated high mortality, mechanical ventilation, vasopressor requirement, and a high incidence of intensive care unit admission [16-18]. Due to the aforementioned reasons, we added serum lactate as a new variable in the MLRINEC score. All six original LRINEC score variables and serum lactate as a continuous or categorical variable were significantly different between the NF and non-NF groups (all $P<0.05$ ) (Table 1).

Figure 1 shows the ROCs for seven variables, which exhibited the discriminating ability of the MLRINEC score, with an AUC ranging from 0.667 (95\% confidence interval (CI), 0.591-0.827) for sodium to 0.898 (95\% CI, 
Table 1 Clinical characteristics between NF and non-NF groups

\begin{tabular}{|c|c|c|c|}
\hline Variable $(n, \%$ or mean \pm SD) & NF group $(n=101)$ & Non-NF group $(n=202)$ & $P$ value \\
\hline Age & $57.1 \pm 19.8$ & $57.0 \pm 19.5$ & 0.91 \\
\hline Sex (male) & $67(66.3 \%)$ & $134(66.3 \%)$ & 1.0 \\
\hline Systolic blood pressure & $103 \pm 18.3$ & $111 \pm 15.1$ & 0.53 \\
\hline Heart rate & $98 \pm 13.5$ & $102 \pm 16.7$ & 0.32 \\
\hline Body temperature & $36.8 \pm 1.9$ & $36.5 \pm 2.3$ & 0.84 \\
\hline Malignancy & 7 (6.9\%) & $12(5.9 \%)$ & 0.87 \\
\hline Heart disease & 15 (14.9\%) & $27(13.4 \%)$ & 0.75 \\
\hline Pulmonary disease & $11(10.9 \%)$ & $23(11.4 \%)$ & 0.59 \\
\hline Liver disease & $35(34.7 \%)$ & $30(14.9 \%)$ & $<0.01^{*}$ \\
\hline Kidney disease & 39 (38.6\%) & $25(12.4 \%)$ & $<0.01^{*}$ \\
\hline Peripheral vascular disease & $9(8.9 \%)$ & $12(5.9 \%)$ & $0.03^{*}$ \\
\hline Diabetes mellitus & $36(35.6 \%)$ & $21(10.4 \%)$ & $<0.01^{*}$ \\
\hline Hypertension & $15(14.9 \%)$ & $28(13.9 \%)$ & 0.18 \\
\hline Immunosuppressants use & $6(5.9 \%)$ & $10(5.0 \%)$ & 0.94 \\
\hline CRP & $75.6 \pm 21.6$ & $29.4 \pm 19.7$ & $<0.01^{*}$ \\
\hline CRP > $30(\mathrm{mg} / \mathrm{dL})$ & $58(57.4 \%)$ & $49(24.3 \%)$ & $<0.01^{*}$ \\
\hline WBC & $16.2 \pm 6.4$ & $11.1 \pm 3.6$ & $0.01^{*}$ \\
\hline WBC $>15\left(\times 10^{4} / \mathrm{uL}\right)$ & $41(40.6 \%)$ & $51(25.2 \%)$ & $<0.01^{*}$ \\
\hline Hemoglobin & $10.5 \pm 3.8$ & $12.1 \pm 2.9$ & $0.04^{*}$ \\
\hline Hemoglobin < $11(\mathrm{~g} / \mathrm{dL})$ & $38(37.6 \%)$ & $48(23.8 \%)$ & $0.02^{*}$ \\
\hline Blood glucose & $168 \pm 47.1$ & $132 \pm 35.8$ & $0.02^{*}$ \\
\hline Blood glucose $\geqq 180(\mathrm{mg} / \mathrm{dL})$ & $29(28.7 \%)$ & $25(12.4 \%)$ & $<0.01^{*}$ \\
\hline Sodium & $135 \pm 4.5$ & $139 \pm 3.6$ & $0.03^{*}$ \\
\hline Sodium < $135(\mathrm{mEq} / \mathrm{L})$ & $28(27.7 \%)$ & $24(11.9 \%)$ & $0.01^{*}$ \\
\hline Lactate & $18.3 \pm 6.5$ & $10.6 \pm 4.8$ & $<0.01^{*}$ \\
\hline Lactate > $18(\mathrm{mg} / \mathrm{dL})$ & $32(31.7 \%)$ & $22(10.9 \%)$ & $<0.01^{*}$ \\
\hline Creatinine & $1.6 \pm 0.7$ & $1.2 \pm 0.4$ & $0.02^{*}$ \\
\hline Creatinine $\geqq 1.6$ (mg/dL) & $31(30.7 \%)$ & $24(11.9 \%)$ & $<0.01^{*}$ \\
\hline
\end{tabular}

$C R P$ C-reactive protein, WBC white blood cell

${ }^{*} P<0.05$

0.842-0.961) for serum lactate level (all $P<0.05$ ). The optimal cutoff values were $30 \mathrm{mg} / \mathrm{dL}$ for C-reactive protein (CRP), $15 \times 10^{4} / \mathrm{uL}$ for white blood cell (WBC) count, $180 \mathrm{mg} / \mathrm{dL}$ for blood glucose, $11 \mathrm{~g} / \mathrm{dL}$ for hemoglobin, and $135 \mathrm{mEq} / \mathrm{L}$ for sodium. Their corresponding sensitivity was low to high, from 0.498 for creatinine level to 0.893 for lactate, whereas their specificity was moderate to high, from 0.554 for sodium to 0.912 for serum creatinine (Table 2).

Table 3 describes the association of the variables with $\mathrm{NF}$, based on which the corresponding score was assigned. CRP $>30 \mathrm{mg} / \mathrm{dL}$ and serum lactate $>18 \mathrm{mg} /$ $\mathrm{dL}$ were assigned the highest score of 4 points; serum creatinine $\geq 1.6 \mathrm{mg} / \mathrm{dL}$ and comorbid liver disease were assigned the score of 3 points; and WBC count $>15 \times$ $10^{4} / \mathrm{uL}$, hemoglobin $<11 \mathrm{~g} / \mathrm{dL}$, and blood glucose $\geq 180$ $\mathrm{mg} / \mathrm{dL}$ were assigned the score of 2 points. Sodium levels of $<135 \mathrm{mEq} / \mathrm{L}$ were assigned 1 point. We estimated the total score for each patient based on the assigned score of eight variables and constructed the combined ROC. The results showed that the MLRINEC score had a sensitivity of $91.8 \%$ and a specificity of 88.4\%, and the AUC was 0.893 (95\% CI, 0.723-0.948; $P$ $<0.01$ ) (Fig. 2).

\section{Discussion}

NF should be treated early and aggressively, and a prompt surgical intervention can prevent high-risk factors that lead to mortality. A prediction model based on laboratory markers may be useful in its early stage. Based on the original LRINEC score proposed by Wong et al. [9], we made some modifications to optimize the 


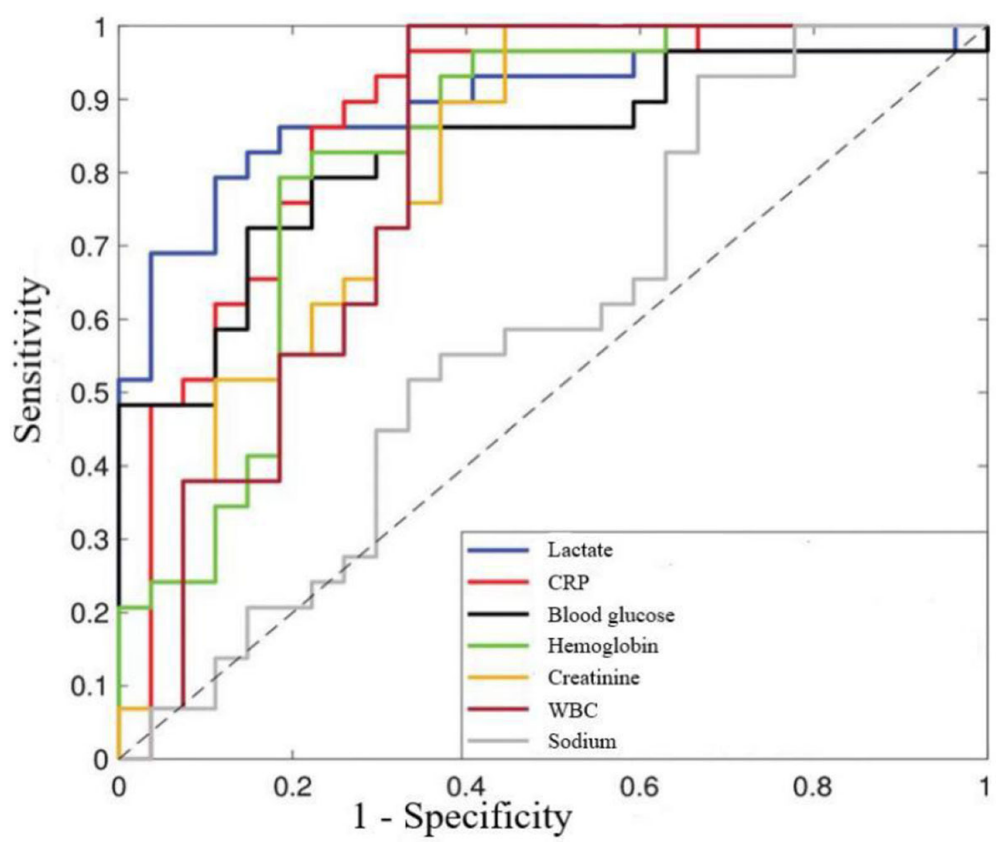

Fig. 1 The ROC and AUC for the CRP, WBC, blood glucose, serum lactate creatinine, sodium and hemoglobin. Their respective AUC from 0.667 ( $95 \% \mathrm{Cl}, 0.591$ to 0.827$)$ to $0.898(95 \% \mathrm{Cl}, 0.842$ to 0.961$)$

original LRINEC score to the MLRINEC score. The results showed that the MLRINEC score could discriminate NF from other soft-tissue infections, with high sensitivity $(91.8 \%)$ and specificity $(88.4 \%)$ when the cutoff value was determined to be 12 points, corresponding to the AUC of 0.893 (95\% CI, 0.723-0.948; $P<0.01$ ).

Because NF and its rapidly progressive infection remain associated with high mortality, the LRINEC score, developed by Wong et al. [9] based on readily available laboratory markers, has been consistently evaluated for its efficacy in various studies. Variable sensitivity ranging from 28.6 to $88.5 \%$ [10, 19-22] was found. These results may be associated with race, ethics, demographics, bacterial species, and timing of blood sampling for laboratory tests. Besides, some well-established comorbidities associated with infectious diseases, such as diabetes and kidney disease, and the use of immunosuppressants are not included in the original LRINEC score. In the MLRINEC score, we made several modifications to the original LRIN EC score. Firstly, we added liver disease, which was significantly more prevalent in patients with NF than in patients without NF and it was also independently associated with NF. Besides, we added serum lactate level, which was confirmed to be associated with critical conditions and NF mortality [23]. Second, we redefined the cut-off values for CRP, total WBC count, and hemoglobin level to be $30 \mathrm{mg} / \mathrm{dL}, 15 \times$ $10^{4} / \mathrm{uL}$, and $11 \mathrm{~g} / \mathrm{dL}$, respectively. At such cutoff values, each variable could discriminate NF from

Table 2 The optimal cut-off value, AUC, and ROC for calculated variables

\begin{tabular}{|c|c|c|c|c|c|c|c|}
\hline Variable & AUC & $\begin{array}{l}95 \% \mathrm{Cl} \\
\text { Lower limit }\end{array}$ & $\begin{array}{l}95 \% \mathrm{Cl} \\
\text { Upper limit }\end{array}$ & $P$ value & Cut-off value & Sensitivity & Specificity \\
\hline CRP & 0.863 & 0.803 & 0.927 & $<0.01^{*}$ & 30 mg/dL & 0.861 & 0.873 \\
\hline WBC & 0.691 & 0.598 & 0.792 & $0.02^{*}$ & $15 \times 10^{4} / \mathrm{uL}$ & 0.528 & 0.916 \\
\hline Blood glucose & 0.765 & 0.671 & 0.856 & $<0.01^{*}$ & 180 mg/dL & 0.692 & 0.758 \\
\hline Creatinine & 0.728 & 0.639 & 0.823 & $<0.01^{*}$ & 1.6 mg/dL & 0.498 & 0.951 \\
\hline $\mathrm{Hb}$ & 0.734 & 0.645 & 0.815 & $0.01^{*}$ & $11 \mathrm{~g} / \mathrm{dL}$ & 0.682 & 0.765 \\
\hline Sodium & 0.667 & 0.591 & 0.827 & $0.02^{*}$ & 135 mEq/L & 0.883 & 0.554 \\
\hline Lactate & 0.898 & 0.842 & 0.961 & $<0.01^{*}$ & 18 mg/dL & 0.893 & 0.885 \\
\hline
\end{tabular}

Cl confidence interval, CRP C-reactive protein, WBC white blood cell, $\mathrm{Hb}$ hemoglobin ${ }^{*} P<0.05$ 
Table 3 Assigned score for variables based on association with NF

\begin{tabular}{|c|c|c|c|c|}
\hline \multirow[t]{2}{*}{ Variables } & \multicolumn{2}{|c|}{ Association magnitude with NF } & \multirow[t]{2}{*}{$P$ value } & \multirow{2}{*}{$\begin{array}{l}\text { Assigned } \\
\text { score }\end{array}$} \\
\hline & $\overline{\mathrm{OR}}$ & $95 \% \mathrm{Cl}$ & & \\
\hline $\mathrm{CRP}>30(\mathrm{mg} / \mathrm{dL})$ & 4.32 & $1.95-9.18$ & $<0.01^{*}$ & 4 \\
\hline WBC $>15\left(\times 10^{4} / \mathrm{uL}\right)$ & 2.38 & $1.27-6.37$ & $0.01^{*}$ & 2 \\
\hline Hemoglobin < $11(\mathrm{~g} / \mathrm{dL})$ & 2.14 & $2.01-9.53$ & $0.02^{*}$ & 2 \\
\hline Blood glucose $\geqq 180(\mathrm{mg} / \mathrm{dL})$ & 2.48 & $1.36-5.12$ & $<0.01^{*}$ & 2 \\
\hline Sodium < 135 (mEq/L) & 1.38 & $1.04-5.88$ & $0.02^{*}$ & 1 \\
\hline Creatinine $\geqq 1.6$ (mg/dL) & 2.85 & $1.98-7.55$ & $0.01^{*}$ & 3 \\
\hline Lactate > 18 (mg/dL) & 4.49 & $2.66-12.54$ & $<0.01^{*}$ & 4 \\
\hline Liver disease & 2.76 & $1.58-6.49$ & $<0.01^{*}$ & 3 \\
\hline
\end{tabular}

$\mathrm{Cl}$ confidence interval, $C R P$ C-reactive protein, $W B C$ white blood cell, $H b$ hemoglobin, $N F$ necrotizing fasciitis, $O R$ odds ratio

${ }^{*} P<0.05$

other soft-tissue infections, and each variable was identified to be independently associated with NF after adjusting for confounders.

The clinical value of the MLRINEC score was determined by its sensitivity and specificity. The MLRINEC score could stratify patients into high- and low-risk categories for NF and help make critical decisions for duty surgeons. For high-risk patients, serial MLRINEC score monitoring may be useful for stopping the progression of NF. An early and aggressive surgical intervention may reduce mortality and related complications in high-risk patients. In the MLRINEC score, we dichotomized the laboratory variables but did not consider extreme cases, such as leukopenia, sepsis, and hematologic malignancy $[24,25]$. These should alert physicians of the possibility of the presence of life-threatening conditions.

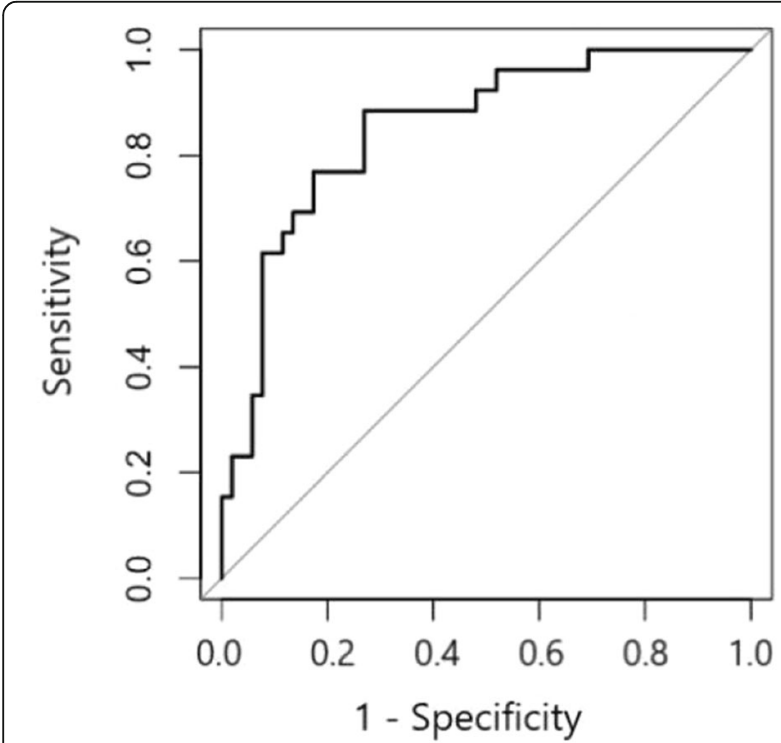

Fig. 2 This figure shows the ROC for the modified LRINEC, sensitivity of $91.8 \%$, and specificity of $88.4 \%$, corresponding to an optimal cutoff of 12 points and the AUC of 0.893
This study still has some limitations. First, this study lacks external validation. The validity of the MLRINEC score still requires other studies to confirm. Second, the retrospective design of this study had its inherent limitation in data collection, such as unverified comorbidities. Third, the sample size is relatively small due to the rarity of NF. Fourth, this study aimed to develop a modified score based on the LRINEC, so we did not include other possibly closely related inflammatory/immune variables, such as serum albumin and blood coagulation factors.

\section{Conclusions}

In summary, we developed the MLRINEC score using a retrospective design. The risk stratification score demonstrated high sensitivity and specificity in the differential diagnosis of NF and other soft-tissue infectious and may be useful in providing necessary information for reasonable suspicion of NF. The validity of the MLRINEC score still needs to be confirmed by further studies.

\section{Abbreviations \\ AUC: Area under curve; Cl: Confidence interval; CRP: C-reactive protein; ED: Emergency department; Hb: Hemoglobin; ICD-9-CM: International Classification of Diseases, Ninth Revision, Clinical Modification; LRIN EC: Laboratory Risk Indicator for Necrotizing Fasciitis; MRI: Magnetic resonance imaging; NF: Necrotizing fasciitis; OR: Odds ratio; ROC: Receiver- operating characteristics; SD: Standard deviation; WBC: White blood cell}

\section{Acknowledgements}

The authors thank all the participants who participated in this study.

\section{Authors' contributions}

$\mathrm{PH}$ Wu conceived of the study, participated in its design and coordination, and helped to draft the manuscript. CP Chang participated in drafting the manuscript and statistical analysis. KH Wu participated in the design of study and drafted the manuscript. SR Wu and CT Hsiao participated in statistical analysis. All authors read and approved the final manuscript.

\section{Funding}

The study was supported by Chang Gung Memorial Hospital. (CORPG6E0043) (CMRPG6J0111) (CMRPG6J0112)

Availability of data and materials

All the data will be available upon motivated request to the corresponding author of the present paper. 


\section{Declarations}

\section{Ethics approval and consent to participate}

The institutional review board of Chia-yi Chang Gung Memorial Hospital (IRB number:100-4178B0C504 and 201900447B0C601) and Kaohsiung Veterans General Hospital (IRB number: VGHKS18-CT6-04) were approved this retrospective study. Consent to participate was not applicable.

\section{Consent for publication}

Not applicable

\section{Competing interests}

The authors declare that they have no competing interests.

\section{Author details}

'Department of Emergency Medicine, Chang Gung Memorial Hospital, No.6, Sec. W., Jiapu Rd., Puzi City, Chiayi County 613, Taiwan (R.O.C.). 'Department of Medicine, Chang Gung University, Taoyuan, Taiwan. ${ }^{3}$ Department of Pediatrics, Kaohsiung Veterans General Hospital, Kaohsiung, Taiwan.

Received: 19 April 2021 Accepted: 18 May 2021

Published online: 26 May 2021

\section{References}

1. Wong C-H, Chang H-C, Pasupathy S, Khin L-W, Tan J-L, Low C-O. Necrotizing fasciitis: clinical presentation, microbiology, and determinants of mortality. J Bone Joint Surg Am. 2003:85-A:1454-60.

2. Headley AJ. Necrotizing soft tissue infections: a primary care review. Am Fam Physician. 2003;68(2):323-8.

3. Ozalay M, Ozkoc G, Akpinar S, Hersekli MA, Tandogan RN. Necrotizing softtissue infection of a limb: clinical presentation and factors related to mortality. Foot Ankle Int. 2006;27(8):598-605. https://doi.org/10.1177/10711 0070602700806

4. Roje Z, Roje Z, Matić D, Librenjak D, Dokuzović S, Varvodić J. Necrotizing fasciitis: literature review of contemporary strategies for diagnosing and management with three case reports: torso, abdominal wall, upper and lower limbs. World J Emerg Surg. 2011;6(1):46. https://doi.org/10.1186/17497922-6-46.

5. Hakkarainen TW, Kopari NM, Pham TN, Evans HL. Necrotizing soft tissue infections: review and current concepts in treatment, systems of care, and outcomes. Curr Probl Surg. 2014;51(8):344-62. https://doi.org/10.1067/j. cpsurg.2014.06.001.

6. Chang C-P, Hsiao C-T, Lin C-N. Risk factors for mortality in the late amputation of necrotizing fasciitis: a retrospective study. World J Emerg Surg. 2018;13:1-1.

7. Kim MC, Kim S, Cho EB, Lee GY, Choi SH, Kim SO, et al. Utility of magnetic resonance imaging for differentiating necrotizing fasciitis from severe cellulitis: a Magnetic Resonance Indicator for Necrotizing Fasciitis (MRINEC) Algorithm. J Clin Med. 2020;9(9):3040.

8. Lin CN, Hsiao CT, Chang CP, Huang TY, Hsiao KY, Chen YC, et al. The relationship between fluid accumulation in ultrasonography and the diagnosis and prognosis of patients with necrotizing fasciitis. Ultrasound Med Biol. 2019 Jul;45(7):1545-50. https://doi.org/10.1016/j.ultrasmedbio.201 9.02.027.

9. Wong CH, Khin LW, Heng KS, Tan KC, Low CO. The LRINEC (Laboratory Risk Indicator for Necrotizing Fasciitis) score: a tool for distinguishing necrotizing fasciitis from other soft tissue infections. Crit Care Med. 2004;32(7):1535-41. https://doi.org/10.1097/01.CCM.0000129486.35458.7D

10. Tan J, Koh B, Hong C, Lim S, Liang S, Chan G, et al. A comparison of necrotising fasciitis in diabetics and non-diabetics: a review of 127 patients. Bone Joint J. 2016;11:1563-8.

11. Holland MJ. Application of the Laboratory Risk Indicator in Necrotising Fasciitis (LRINEC) score to patients in a tropical tertiary referral centre. Anaesth Intensive Care. 2009;37(4):588-92. https://doi.org/10.1177/031 $0057 \times 0903700416$

12. Abdullah M, McWilliams B, Khan SU. Reliability of the Laboratory Risk Indicator in Necrotising Fasciitis (LRINEC) score. Surgeon. 2019;17(5):309-18. https://doi.org/10.1016/j.surge.2018.08.001

13. Johnson L, Crisologo P, Sivaganesan S, Caldwell C, Henning J. Evaluation of the Laboratory Risk Indicator for Necrotizing Fasciitis (LRINEC) score for detecting necrotizing soft tissue infections in patients with diabetes and lower extremity infection. Diabetes Res Clin Pract. 2020;171:108520.
14. Khosravani H, Shahpori R, Stelfox HT, et al. Occurrence and adverse effect on outcome of hyperlactatemia in the critically ill. Crit Care. 2009;13(3):R90. https://doi.org/10.1186/cc7918.

15. Mikkelsen ME, Miltiades AN, Gaieski DF, et al. Serum lactate is associated with mortality in severe sepsis independent of organ failure and shock. Crit Care Med. 2009;37:1670-7.

16. Tang Y, Choi J, Kim D. et al, Clinical predictors of adverse outcome in severe sepsis patients with lactate 2 to $4 \mathrm{mM}$ admitted to the hospital. QJM. Published Online First: 4 Sep 2014. https://doi.org/10.1093/qjmed/hcu186.

17. Azevedo LC, Park M, Salluh Jl, et al. Clinical outcomes of patients requiring ventilatory support in Brazilian intensive care units: a multicenter, prospective, cohort study. Crit Care. 2013;17:R63. https://doi.org/10.1186/cc12594.

18. Bakker J, Gris P, Coffernils M, et al. Serial blood lactate levels can predict the development of multiple organ failure following septic shock. Am J Surg. 1996;171:221-6.

19. Al-Hindawi A, McGhee J, Lockey J, Vizcaychipi M. Validation of the laboratory risk indicator for necrotising fasciitis scoring system (LRINEC) in a Northern European population. J Plast Reconstr Aesthet Surg. 2017;70(1): 141-3. https://doi.org/10.1016/j.bjps.2016.05.014.

20. Ogawa M, Yokoo S, Takayama Y, Kurihara J, Makiguchi T, Shimizu T. Laboratory Risk Indicator for Necrotizing Fasciitis of the Oro-Cervical Region (LRINEC-OC): A Possible Diagnostic Tool for Emergencies of the Oro-Cervical Region. Emerg Med Int. 2019;2019:1573453.

21. Captain N, Anandi A. A study on validation of modified LRINEC scoring system for the diagnosis of necrotising fasciitis in patients with soft tissue infection. Int Arch Integr Med. 2020;7(3):35-40.

22. Putnam LR, Richards MK, Sandvall BK, Hopper RA, Waldhausen JH, Harting MT. Laboratory evaluation for pediatric patients with suspected necrotizing soft tissue infections: a case-control study. J Pediatr Surg. 2016;51(6):1022-5. https://doi.org/10.1016/j.jpedsurg.2016.02.076.

23. Chang CP, Fann WC, Wu SR, Lin CN, Hsiao CT. Lactate on emergency department arrival as a predictor of in-hospital mortality in necrotizing fasciitis: a retrospective study. J Orthop Surg Res. 2019;14(1):73. https://doi. org/10.1186/s13018-019-1108-y

24. Bone RC, Balk RA, Cerra FB, Dellinger RP, Fein AM, Knaus WA, et al. Definitions for sepsis and organ failure and guidelines for the use of innovative therapies in sepsis. The ACCP/SCCM Consensus Conference Committee. American College of Chest Physicians/Society of Critical Care Medicine. Chest. 1992; 101(6):1644-55. https://doi.org/10.1378/chest.101.6.1644.

25. Benoit DD, Vandewoude KH, Decruyenaere JM, Hoste EA, Colardyn FA Outcome and early prognostic indicators in patients with a hematologic malignancy admitted to the intensive care unit for a life-threatening complication. Crit Care Med. 2003;31(1):104-12. https://doi.org/10.1097/ 00003246-200301000-00017.

\section{Publisher's Note}

Springer Nature remains neutral with regard to jurisdictional claims in published maps and institutional affiliations.

Ready to submit your research? Choose BMC and benefit from:

- fast, convenient online submission

- thorough peer review by experienced researchers in your field

- rapid publication on acceptance

- support for research data, including large and complex data types

- gold Open Access which fosters wider collaboration and increased citations

- maximum visibility for your research: over $100 \mathrm{M}$ website views per year

At BMC, research is always in progress.

Learn more biomedcentral.com/submissions 